\title{
A pandemia da Covid-19 e o aumento de vulnerabilidades
}

\author{
The Covid-19 pandemic and increased vulnerabilities \\ La pandemia de Covid-19 y el aumento de las vulnerabilidades
}

Recebido: 08/07/2021 | Revisado: 11/07/2021 | Aceito: 12/07/2021 | Publicado: 22/07/2021

\author{
Rogério Teixeira de Oliveira \\ ORCID: https://orcid.org/0000-0003-2609-9494 \\ Universidade do Estado do Rio de Janeiro, Brasil \\ E-mail:rtdoacad@gmail.com
}

\begin{abstract}
Resumo
O presente artigo realizou uma análise sobre a pandemia da Covid-19, a fim de verificar sua correlação com o aumento das vulnerabilidades. Assim, metodologicamente foi utilizada a pesquisa bibliográfica e documental, a partir de uma abordagem qualitativa. O objetivo principal da análise foi categorizar vulnerabilidades e realizar as imbricações da pandemia com a referida categoria, inscrita no modo capitalista de produção a partir de seu direcionamento neoliberal. Como objetivos específicos esta pesquisa se propôs a identificar os grupos mais vulneráveis atingidos pela crise sanitária. Nesse sentido foi possível constatar como resultados que a pandemia atinge com maior força os grupos mais vulneráveis e empobrecidos da população ao redor do mundo, ou seja, a pandemia não tem o mesmo efeito para todos. O estudo finaliza apresentando como possíveis saídas para a crise pandêmica a superação do modo capitalista de produção, o enfraquecimento da direita, o fortalecimento do Estado e a maior participação da comunidade.
\end{abstract}

Palavras-chave: Covid-19; Vulnerabilidades; Neoliberalismo.

\begin{abstract}
This article carried out an analysis of the Covid-19 pandemic in order to verify its correlation with the increase in vulnerabilities. Thus, bibliographic and documentary research was methodologically used from a qualitative approach. The main objective of the analysis was to categorize vulnerabilities and perform the imbrications of the pandemic with this category, inscribed in the capitalist mode of production from its neoliberal direction. As specific objectives, this research aimed to identify the most vulnerable groups affected by the health crisis. In this sense, it was possible to observe as results that the pandemic affects with greater force the most vulnerable and impoverished groups of the population around the world, that is, the pandemic does not have the same effect for all. The study concludes by presenting as possible ways out of the pandemic crisis the overcoming of the capitalist mode of production, the weakening of the right, the strengthening of the state and the greater participation of the community.
\end{abstract}

Keywords: Covid-19; Vulnerabilities; Neoliberalism.

\section{Resumen}

Este artículo realizó un análisis de la pandemia de Covid-19 con el fin de verificar su correlación con el aumento de vulnerabilidades. Así, la investigación bibliográfica y documental fue utilizada metodológicamente desde un enfoque cualitativo. El objetivo principal del análisis fue categorizar vulnerabilidades y realizar las imbricaciones de la pandemia con esta categoría, inscrita en el modo de producción capitalista desde su dirección neoliberal. Como objetivos específicos, esta investigación tuvo como objetivo identificar los grupos más vulnerables afectados por la crisis sanitaria. En este sentido, se pudo observar como resultados que la pandemia afecta con mayor fuerza a los grupos más vulnerables y empobrecidos de la población de todo el mundo, es decir, la pandemia no tiene el mismo efecto para todos. El estudio concluye presentando como posibles salidas a la crisis pandémica la superación del modo de producción capitalista, el debilitamiento de la derecha, el fortalecimiento del Estado y la mayor participación de la comunidad.

Palabras clave: Covid-19; Vulnerabilidades; Neoliberalismo.

\section{Introdução}

Ante a pandemia da Covid-19, a situação de precariedade de grupos sociais vulneráveis foi claramente acentuada e exposta. A Organização Mundial de Saúde (OMS) declarou a Covid-19 como uma pandemia em 11 de março de 2020. Conforme Santos (2020) a pandemia agravou uma crise que já estava estabelecida derivando daí sua periculosidade. 
Nesse sentido, questões de saúde, população em situação de rua, envelhecimento, educação, renda e trabalho, território, infraestrutura, saneamento e habitação e segurança alimentar são essenciais na análise da realidade pandêmica.

Dados do relatório "Estado da Insegurança Alimentar e Nutricional no Mundo" em 2019 da Organização das Nações Unidas (ONU) trazem que mais de 820 milhões de pessoas passavam fome no mundo, ou seja, uma em cada nove pessoas. Ainda, mostrou que dois bilhões de pessoas sofriam com insegurança alimentar moderada ou grave (ONU, 2019).

Em relação à questão sanitária, a partir do aumento do número de infectados, a OMS orientou que as pessoas aderissem ao isolamento social como estratégia para evitar novas infecções e minimização do colapso nos sistemas de saúde. Em 28 de abril de 2020 a ONU (2020) reforçou esse posicionamento e reiterou a importância da segurança e da saúde no trabalho.

Assim, a partir de pesquisa bibliográfica e a pesquisa em sites de Órgãos públicos e da imprensa, com o objetivo de discutir o conceito de vulnerabilidade e suas correlações com a pandemia da Covid-19. Num segundo momento foi realizada uma análise sobre neoliberalismo, seus rebatimentos no enfrentamento da doença e apresentadas como considerações finais as propostas de superação da realidade pandêmica.

\section{Metodologia}

O presente estudo realizou uma abordagem qualitativa, a partir de revisão bibliográfica sobre a questão da emergência da pandemia da Covid-19 e das vulnerabilidades sociais acentuadas pela mesma.

A pesquisa qualitativa "fornece os dados básicos para o desenvolvimento e a compreensão das relações entre os atores sociais e sua situação. O objetivo é uma compreensão detalhada das crenças, atitudes, valores e motivação, em relação aos comportamentos das pessoas em contextos sociais específicos." (Gaskell, 2002, p. 65). Ainda a pesquisa qualitativa é "uma atividade situada que localiza o observador no mundo. A pesquisa qualitativa consiste em um conjunto de práticas materiais interpretativas que tornam o mundo visível [...] envolve uma abordagem interpretativa e naturalística do mundo.” (Denzin \& Lincoln, 2011, p. 3).

Em relação à coleta de dados da revisão bibliográfica esta "é realizada a partir do levantamento de referências teóricas já analisadas e publicadas por meios escritos e eletrônicos, como livros, artigos científicos, páginas de web sites [...]" (Fonseca, 2002, p. 32). Assim, o estudo subsidiou o tratamento analítico da categoria vulnerabilidade e neoliberalismo na emergência da crise da pandemia da Covid-19.

\section{Resultados e Discussão}

A exposição da população mundial à Covid-19 colocou em relevo milhões de pessoas por causa de suas vulnerabilidades sociais. O termo vulnerabilidade não é algo determinado e pronto, mas resultante de "múltiplos fatores que fragilizam os sujeitos no exercício de sua cidadania" (Carmo \& Guizardi, 2018, p. 1). Vulnerabilidade pode ser entendida como "termo interdisciplinar aplicável a diferentes campos temáticos, remetendo ao sentido de fragilidade. Na área da saúde, o conceito de vulnerabilidade tem presença na Bioética, Saúde Mental, Saúde Ambiental, Epidemiologia" (Sevalho, 2018, p.179). Ainda, Sevalho (2018) afirma que vulnerabilidade se relaciona com categorias, tais como: epidemiologia, saúde coletiva, proteção social, estilo de vida, medicina social, solidariedade, relações de direitos e justiça. Assim, vulnerabilidade pode ter vários sentidos e ser entendida a partir de um caráter transitório; visto que as pessoas não são vulneráveis, mas estão vulneráveis por causa de suas condições sociais. É importante considerar também o conceito de seguridade social, expressa na Constituição Federal de 1988; visto que direitos e políticas públicas de saúde, previdência e assistência social se relacionam diretamente com a questão: "A seguridade social compreende um conjunto integrado de ações de iniciativa dos poderes 
públicos e da sociedade, destinadas a assegurar os direitos relativos à saúde, à previdência e à assistência social.” (Brasil, 1988).

Vulnerabilidade está também correlacionada com o surgimento da questão social e do capitalismo. Capitalismo pode ser definido como "qualquer formação social em que os processos de circulação e acumulação do capital são hegemônicos e dominantes no fornecimento e moldagem das bases materiais, sociais e intelectuais da vida social” (Harvey, 2016, p. 19). Em relação ao surgimento da questão social tem-se que "pela primeira vez na história registrada, a pobreza crescia na razão direta em que aumentava a capacidade social de produzir riquezas" (Netto, 2005, p. 153). Esse relevo que a questão social teve no final do século XIX se deu através da metamorfose social que se conformou, a partir da correlação de forças das classes que emergiam. Netto (2005) ainda afirma que existe também um direcionamento que busca tratar a questão social não como resultante de um processo coletivo, mas culpabilizando o sujeito individualmente pela sua condição. Na tentativa de individualizar a questão social, esses sujeitos são classificados como pobres, miseráveis, desmotivados, preguiçosos e recai sobre os mesmos a culpa individualizada por sua transitável e vulnerável situação socioeconômica.

Santos (2020, pp. 15-20) apresenta como sujeitos vulneráveis as mulheres, trabalhadores precarizados em suas múltiplas possibilidades, pessoas sem abrigo, pessoas em situação de rua, moradores das periferias, pobres das favelas, refugiados em campos de internamento, imigrantes sem documentos, deficientes e idosos. Também inclui as pessoas presas, pessoas com doença mental e afirma que o pânico generalizado leva à invisibilidade em relação a esses dois últimos grupos. Antunes (2018) traz em sua descrição como sujeitos em situação de vulnerabilidade: imigrantes pobres, mulheres brancas, imigrantes negras, indígenas e amarelas inseridas, portanto, "em um amplo espectro da população excedente de trabalhadores e trabalhadoras, que Marx denominou superpopulação relativa ou exército de reserva" (Antunes, 2018, p. 54). Assim, é preciso levar em consideração uma série de fatores dentro das contradições do capitalismo e realizar-se um esforço permanente no enfrentamento das vulnerabilidades e na busca da igualdade social

Sentimentos como os de desqualificação frente aos longos períodos de inserção em programas assistenciais e não inserção no mercado de trabalho; de impotência para o enfrentamento das adversidades, ou de incompetência por não compartilhamento de saberes dominantes, ainda que se configurem em situações vulnerabilizantes, com tendência a provocar fragilização de vínculos sociais e isolamento, não devem ser justificativa para direcionar práticas disciplinadoras e moralizantes sobre o público das políticas de saúde e assistência social. O reconhecimento das potencialidades dos cidadãos como sujeitos de direitos e a necessidade de se descortinar as implicações estruturais que os colocam em situação de vulnerabilidade, requerendo organização para a exigência ao poder público de acesso mais igualitário a oportunidades, fazem parte de uma conduta que pressupõe esforço constante (Carmo \& Guizardi, 2018, p. 9).

Carmo e Guizardi (2018) apontam ainda como elementos principais no combate às vulnerabilidades: a garantia de direitos pelo poder público, participação popular ativa, fortalecimento dos espaços dos trabalhadores do SUS e do SUAS, dos arranjos intersetoriais, da interação interdisciplinar e do respeito à liberdade dos sujeitos de direitos. Nesse sentido é importante relembrar o protagonismo que movimentos sociais tiveram nos anos 1980, período reconstrução democrática.

Ante a realidade pandêmica é preciso maior aproximação entre saúde e assistência, ou seja, uma integração maior entre o Sistema Único de Saúde - SUS e o Sistema Único de Assistência Social - SUAS, a fim de reduzir exigências, por exemplo, do acesso da população em situação de rua às políticas públicas em tempos de pandemia (Ceensp, 2020). Conforme o Boletim Epidemiológico da Fiocruz, no mês novembro de 2020, persistem os "limites na infraestrutura e defasagem dos registros nos sistemas de informação" e sugere uma

estratégia de enfrentamento da pandemia que articule a vigilância em saúde, com testes e identificação ativa de casos e contatos, isolamento dos casos, quarentena dos contatos, e que seja combinada com medidas de distanciamento social e de redução da exposição da população a situações de risco de transmissão do vírus Sars-CoV-2. (Fiocruz, 2020a) 
A Fiocruz identificou que, em novembro de 2020, $75 \%$ da população dependente do SUS estão tendo dificuldades para acessar leitos para tratamento da doença (Fiocruz, 2020a). Tais resultados demonstram que a doença continuava avançando e que havia uma incapacidade do governo enfrentar a doença.

Assim, o direcionamento neoliberal do governo; que prioriza políticas econômicas e não a proteção social é questão que precisa ser discutida e está também em evidência durante a crise sanitária.

O neoliberalismo como projeto político do capitalismo, com a posição de individualização e culpabilização pessoal das vulnerabilidades contribui para o acirramento das desigualdades. Harvey (2013) traz que a configuração política e econômica que atravessamos está intrinsecamente relacionada ao capitalismo e às suas crises cíclicas: a de 1929, a crise do petróleo nos anos 1970, a crise financeira de 2008 e agora a crise da pandemia da Covid-19. A partir dos anos 1980, a globalização da economia trouxe um direcionamento sociopolítico neoliberal abrangente globalmente e que apresenta características tais como: "ajuste fiscal", xenofobia, migrações, pandemias, bolhas imobiliárias, desregulamentações de direitos, aumento da pobreza, terceirização de serviços e crescimento de capital volátil, em detrimento da produção efetiva (Harvey, 2013). Harvey (2012) afirma que as crises provocadas pelo capitalismo trazem consigo a anuência de determinados grupos; tendo em vista esses defenderem que tais crises são necessárias periodicamente, ou seja, entendem as crises como respostas às suas próprias contradições. É preciso “valorizar a vida no lugar do lucro!” (Mancebo, 2020, p. 12).

A crise mundial decorrente da pandemia da Covid-19 tem tido impactos sociais e econômicos, que mais uma vez dão relevo às contradições do modo capitalista. A quarentena recomendada não alcança todas as pessoas. A recomendação de ficar em casa para os mais vulneráveis não é uma possibilidade factível. A higienização proposta também não é possível para quem vive com mínimos de subsistência, sem água e saneamento básico. Nessa direção, Santos (2020) afirma que a quarentena é mais discriminatória para determinados grupos sociais; visto que tais grupos já são historicamente vulneráveis e tem na crise pandêmica suas vulnerabilidades acentuadas. Reitera a importância do tráfego adequado das informações e critica as fake news em países democráticos, como fator que influi diretamente na questão da letalidade da doença. Raichelis e Yazbek (2018) defendem como essencial a democracia e os direitos sociais ante dissonâncias históricas que possam enfraquecê-los.

Ainda, a não opção por políticas públicas efetivas, que retirem milhões de pessoas da miséria, o incentivo à autonomia "trabalhista" desregulada e o empreendedorismo são escolhas que custam caro ao enfrentamento da pandemia. Tal configuração deixa clara a relação entre o enfretamento à pandemia e os investimentos em políticas públicas delineados no país. Algebaile e Oliveira (2018) criticam posicionamentos nesta direção, ou seja, que colocam o capital antes da priorização da vida. No Brasil, a Emenda constitucional no 95 de 2016 (Brasil, 2016), que limitou investimentos sociais por 20 exercícios e as ações do governo no combate à doença apontam para um cenário desolador para as políticas públicas.

A crise sanitária colocou ainda a categoria trabalho em evidência; visto que a precarização do mesmo tem implicações diretas com a realidade da pandemia. Antunes (2018) reafirma a dependência do trabalho por bilhões de pessoas. Nesse sentido, a instabilidade criada pela pandemia influencia diretamente as relações de trabalho já precarizadas, intermitentes e flexíveis. Dardot e Laval (2016) declaram que dentro dessa realidade há uma "fabricação de sujeitos neoliberais", ou seja, sujeitos apartados de sua consciência de classe e provedores de si mesmos. A Organização Internacional do trabalho (OIT) apresentou em abril de 2020 dados sobre a trágica situação do trabalho no mundo:

A crise econômica causada pela pandemia afetou severamente a capacidade de ganhar a subsistência de quase 1,6 bilhão de trabalhadoras (es) na economia informal (o grupo mais vulnerável no mercado de trabalho), de um total de dois bilhões na economia informal em todo o mundo, e de uma força de trabalho global de 3,3 bilhões de pessoas. Isso se deve a medidas de confinamento e / ou porque essas pessoas trabalham em alguns dos setores mais atingidos pela crise. Estima-se que o primeiro mês da crise tenha resultado em uma queda de 60\% na renda das (os) trabalhadoras (es) informais em todo o mundo. Isso se traduz em uma queda de $81 \%$ na África e nas Américas, $21,6 \%$ na Ásia e no Pacífico e 70\% na Europa e Ásia Central. (OIT, 2020, p. 1) 
O enfrentamento à pandemia tem tido mais êxito com "Os governos com menos lealdade ao ideário neoliberal [...] estão a actuar mais eficazmente contra a pandemia, independentemente do regime político" (Santos, 2020, p. 25). A Fiocruz(2020) alerta que cada região tem suas necessidades específicas e, portanto, a luta contra a pandemia deve levar essas especificidades em conta. Como resultados da pandemia, Santos (2020) apresenta uma relação das lições iniciais apreendidas:

Lição 1 . O tempo político e mediático condiciona o modo como a sociedade contemporânea se apercebe dos riscos que corre;

Lição 2. As pandemias não matam tão indiscriminadamente quanto se julga;

Lição 3. Enquanto modelo social, o capitalismo não tem futuro;

Lição 4. A extrema-direita e a direita hiper-neoliberal ficam definitivamente (espera-se) descreditadas;

Lição 5. O colonialismo e o patriarcado estão vivos e reforçam-se nos momentos de crise aguda e

Lição 6. O regresso do Estado e da comunidade (Santos, 2020, p. 22).

Chomsky (2020) assinala que a pandemia pode contribuir em "favor da assistência universal à saúde e dos problemas mais profundos de nossas sociedades" e que a força da opinião pública é que será responsável por esses resultados. Medeiros(2020) traz que a superação se dará através de uma "luta à morte"; que leve à "crise terminal do sistema" através de organização e ação consciente através da política. Santos (2020) afirma que a quarentena realizada por causa da Covid-19 está inscrita numa quarentena maior; que é a quarentena histórica metamorfoseada pelas contradições do modo capitalista, o qual é preciso superar.

\section{Considerações Finais}

As discussões apresentadas, a partir dos conceitos de vulnerabilidade, neoliberalismo e suas correlações na forma como a pandemia da Covid-19 vêm tomando forma podem contribuir para o seu enfretamento.

O Conceito de vulnerabilidade não é único e estanque e, portanto, a pesquisa não teve a pretensão de esgotar a discussão sobre o tema, nem das possíveis saídas para o período pós-pandemia.

Ainda assim, é possível depreender que a articulação entre as diversas políticas públicas, com relevo à integração entre o SUS e o SUAS; a transparência nos dados epidemiológicos; o combate à fake news; a utilização da experiência acumulada no luta contra a epidemia de HIV/Aids; o fortalecimento de governos que pautem em políticas públicas que minimizem desigualdades e protejam a vida e ainda o protagonismo de movimentos e grupos sociais pautados pelo acesso, garantia e ampliação de direitos são possibilidades que caminham na superação da doença.

O que se tem observado é que o atual quadro de crise pandêmica tem aumentado o número de infectados, penalizado e levado à morte, em maior número, os mais vulneráveis. A doença ressaltou vulnerabilidades e trouxe questões de saúde, educação, proteção social, gênero e raça, modos de vida, controle e vigilância, habitação e trabalho para o centro do debate. Escancarou contradições existentes, infladas pelo modo de produção capitalista e clarificou sua correlação ao direcionamento político e econômico das nações no sentido da proteção econômica e social.

O estudo sugere que futuras pesquisas referentes ao tema analisem as políticas governamentais, as relações sociais e as respectivas interconexões com o meio ambiente. A realização dessas correlações é situação fundamental para entender não só a crise pandêmica da Covid-19, mas o movimento da realidade social. Ainda, os futuros estudos devem se pautar pela defesa do Estado Democrático de Direito e pela efetivação de políticas públicas como forma de luta contra as vulnerabilidades.

\section{Referências}

Algebaile, E., \& Oliveira, F. J. G. de. (2018). A superação do capitalismo em questão: com que práticas, em qual direção? In: XV Coloquio Internacional de Geocrítica Las ciencias sociales y la edificación de una sociedad post-capitalista. Anais. Barcelona.

Antunes, R. Prefácio. (2018). In: Raichelis, R., Vicente, D., Albuquerque, V. (org.). A nova morfologia do trabalho no Serviço Social. São Paulo: Cortez. 
Brasil. (2020). Coronavírus Brasil. https://covid.saude.gov.br/.

Brasil. (1988). Constituição da República Federativa do Brasil de 1988. http://www.planalto.gov.br/ccivil_03/Constituicao/Constituicao.htm

Brasil. (2016). Emenda Constitucional $n^{o}$ 95, de 15 de dezembro de 2016. Altera o Ato das Disposições Constitucionais Transitórias, para instituir o Novo Regime Fiscal, e dá outras providências. http://www.planalto.gov.br/ccivil_03/constituicao/emendas/emc/emc95.htm

Carmo, M. E., \& Guizardi, F. L. (2018). O conceito de vulnerabilidade e seus sentidos para as políticas públicas de saúde e assistência social. Cadernos de Saúde Pública 2018, 34(3):e00101417. https://www.scielo.br/pdf/csp/v34n3/1678-4464-csp-34-03-e00101417

Ceensp. (2020). Vulnerabilidades sociais no contexto da Covid-19. https://portal.fiocruz.br/video/ceensp-vulnerabilidades-sociais-no-contexto-da-covid-19.

Chomsky, N. (2020). Não podemos deixar a Covid-19 nos levar ao autoritarismo. Dossiê Coronavírus e sociedade. Boitempo.

Denzin, N. K., \& Lincoln, Y. S. (2011). Introduction: The discipline and practice of qualitative research. The Sage Handbook of qualitative research (4th ed.), 1-19). Sage.

Dardot, Pierre e Laval, Christian. (2016). A nova razão do mundo. Ensaio sobre a sociedade neoliberal. Boitempo.

Fiocruz. (2020). Fiocruz lança ações de apoio a populações vulneráveis. https://portal.fiocruz.br/noticia/covid-19-fiocruz-lanca-acoes-de-apoio-populacoesvulneraveis

Fiocruz. (2020 a). Boletim Observatório Covid-19 - Semanas epidemiológica 46 e 47. https://portal.fiocruz.br/conteudo-documento/arquivo-tipo-dedocumento/arquivo/boletim-epidemiologico

Fonseca, J. J. S. da. (2002). Metodologia da pesquisa científica. UEC.

Harvey, D. (2012). O enigma do capital e as crises do capitalismo. Boitempo.

Harvey, D. (2013). A importância da imaginação pós-capitalista. http://www.irishleftreview.org

Harvey, D. (2016). 17 contradições e o fim do capitalismo. Boitempo.

Gaskell, G. (2002). Entrevistas individuais e grupais. In: M. W. Bauer, \& G. Gaskell (Orgs.), Pesquisa qualitativa com texto, imagem e som: um manual prático. Vozes.

Kodama, Kaori, Pimenta, Tania Salgado. (2020). Condições de vida e vulnerabilidades nas epidemias: do cólera no século 19 à Covid-19. http://coc.fiocruz.br/index.php/pt/todas-as-noticias/1794-condicoes-de-vida-e-vulnerabilidades-nas-epidemias-do-colera-no-seculo-19-a-covid-

19.html\#.X77U12hKiU1

Mancebo, Deise. (2020). Pandemia e educação superior no Brasil. Revista Eletrônica de Educação. 14, 1-15, e4566131. http://www.reveduc.ufscar.br/index.php/reveduc/article/view/4566/1053

Medeiros, J. (2020). O futuro pós-pandemia: prever e agir. Dossiê Coronavírus e sociedade. Boitempo.

Ministério da Saúde. (2020). Sobre a doença. https://coronavirus.saude.gov.br/sobre-a-doenca

Netto, J. P. (2005). Capitalismo monopolista e serviço social. Cortez.

Organização Internacional do Trabalho [OIT] (2020). Perda de empregos aumenta e quase metade da força de trabalho global corre o risco de perder os meios de subsistência. http://www.ilo.org/brasilia/noticias/WCMS_743197/lang--pt/index.htm.

Organização das Nações Unidas [ONU] (2019). Fome atinge mais de 820 milhões de pessoas no mundo. https://news.un.org/pt/story/2019/07/1680101

Organização das Nações Unidas [ONU] (2020). Stop the pandemic: Safety and health at work can save lives. https://un.org/en/observances/work-safety-day

Raichelis, R., \& Yazbek, M. C. (2018). Estudo avaliativo da implementação do Sistema Único de Assistência Social: uma proposta de investigação em desenvolvimento. In: Encontro Nacional de Pesquisadores em Serviço Social, 16., 2018, Vitória. Anais [...]. UFES.

Santos, B. de S. (2020). A cruel pedagogia do vírus. Edições Almedina. Coimbra.

Sevalho G. (2018). O conceito de vulnerabilidade e a educação em saúde fundamentada em Paulo Freire. Interface (Botucatu), $22(64): 177-188$. 